09

\title{
Высокоэффективное преобразование лазерного излучения высокой плотности
}

\author{
(c) А.Н. Паньчак, П.В. Покровский, Д.А. Малевский, В.Р. Ларионов, М.З. Шварц \\ Физико-технический институт им. А.Ф. Иоффее РАН, Санкт-Петербург, Россия \\ E-mail: a.panchak@mail.ioffe.ru
}

Поступило в Редакцию 6 августа 2018 г.

Представлены результаты исследований полупроводниковых фотопреобразователей лазерного излучения на основе $\mathrm{AlGaAs} / \mathrm{GaAs}$ при величине облученности до $9 \mathrm{~kW} / \mathrm{cm}^{2}$ с сохранением изотермического состояния тестируемых образцов. Это подтверждается логарифмическим ходом регистрируемых зависимостей напряжения холостого хода от плотности мощности подводимого излучения. При максимальной облученности достигнуты значения напряжения холостого хода, близкие к $1.33 \mathrm{~V}$. Показана возможность преобразования лазерного излучения (длина волны $840 \mathrm{~nm}$ ) с КПД более $51 \%$ при плотности мощности $2.5 \mathrm{~kW} / \mathrm{cm}^{2}$.

DOI: 10.21883/PJTF.2019.02.47218.17491

В современных оптико-энергетических системах передача мощности лазерного излучения в большинстве случаев реализуется в рамках концепции „роwerover-fiber“. Такой подход предполагает разработку согласованной системы из источника лазерного излучения (ЛИ), оптического волокна и фотоэлектрического преобразователя (ФП) с гальванической развязкой источника и приемника излучения, электромагнитной совместимостью, помехозащищенностью и пр. [1].

В настоящей работе главным предметом исследования является КПД ФП, работающего при высоких и сверхвысоких облученностях (до $10 \mathrm{~kW} / \mathrm{cm}^{2}$ ), создаваемых ЛИ с длиной волны, близкой к ширине запрещенной зоны полупроводникового материала (длина волны $840 \mathrm{~nm})$. Приведенные данные актуальны для непрерывного (стационарного) или импульсного с частотами до $200 \mathrm{MHz}$ (квазистационарного) режимов подвода излучения к ФП. Важно также отметить, что при малых площадях ФП высокие энергетические облученности не подразумевают одновременно большой интегральной мощности излучения и сверхвысоких рабочих токов. Так, в [2] размер исследуемых образцов не превышал $0.1 \mathrm{~cm}^{2}$, что при подводимой световой мощности в $20 \mathrm{~W}$ соответствует значительной $\left(200 \mathrm{~W} / \mathrm{cm}^{2}\right)$ облученности фотоприемной поверхности. В настоящей работе сверхвысокие облученности также достигаются путем концентрации световых потоков на малых (размером до $7 \cdot 10^{-4} \mathrm{~cm}^{2}$ ) ФП. Важным условием проведения экспериментов являлось исключение радиационного нагрева образцов, что обеспечивалось импульсной подачей лазерного излучения значительной пиковой мощности.

При работе ФП в условиях высокой освещенности главным показателем нагрева $p-n$-перехода является вид зависимости напряжения холостого хода от уровня энергетической облученности [3]. При фототоке $\left(I_{p h}\right)$, много большем темнового тока $\left(I_{0}\right)$, напряжение холо- стого хода $\left(\mathbf{V}_{o c}\right)$ может быть аппроксимировано уравнением

$$
V_{o c} \approx \frac{A k T}{q} \ln \left(\frac{I_{p h}}{I_{0}}\right),
$$

где $A-$ коэффициент „идеальности“ вольт-амперной характеристики, $q$ - величина заряда электрона.

Поскольку фототок зависит от энергетической облученности линейно, при постоянной температуре напряжение холостого хода должно логарифмически зависеть от энергетической облученности.

При преобразовании монохроматического излучения практически снижение неконтролируемого радиационного нагрева достигается уменьшением потерь на термализацию фотогенерированных носителей заряда. Для этого важно согласовать область максимальной спектральной чувствительности ФП, ограниченной в длинноволновой части шириной запрещенной зоны полупроводникового материала, с длиной волны ЛИ.

В настоящей работе были исследованы ФП на основе $\mathrm{AlGaAs} / \mathrm{GaAs}$ с максимальной спектральной чувствительностью (рис. 1) на длинах волн 830-840 nm при комнатной температуре. Спектральная чувствительность остается постоянной при возможных сдвигах длины волны ЛИ в диапазоне $800-850 \mathrm{~nm}$.

Возможным путем поддержания изотермического режима работы $p-n$-перехода является активное охлаждение ФП. При этом необходимо подбирать мощность системы охлаждения таким образом, чтобы компенсировать радиационный разогрев. При значительном тепловом ,давлении“ от ЛИ возникнет дисбаланс тепловых потоков, что в совокупности с инерционностью системы активной температурной стабилизации может приводить к перегреву или переохлаждению ФП, искажая регистрируемые экспериментальные данные. При активном охлаждении поддержание одинаковой во всем ее объеме температуры ФП также оказывается невозможным. В первом приближении поток тепла фотоактивная 


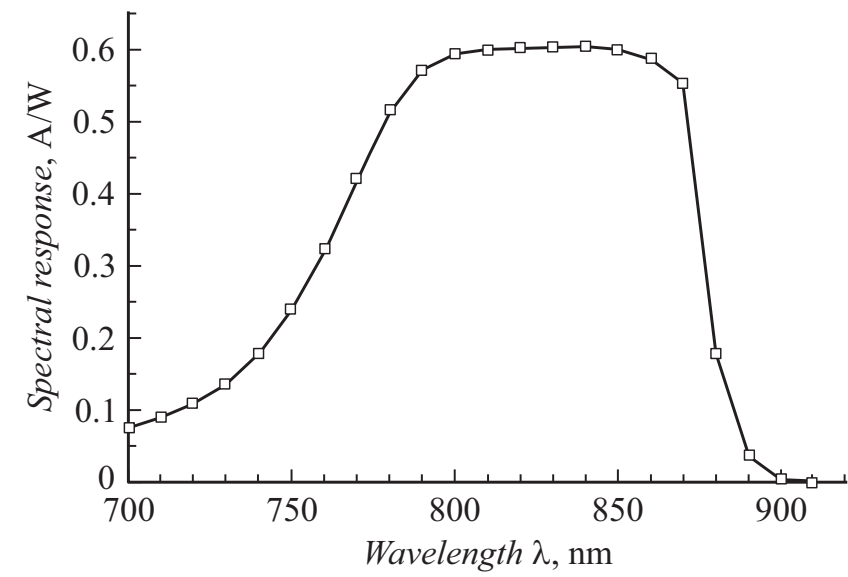

Рис. 1. Зависимость спектральной чувствительности от длины волны облучения исследуемого ФП на основе $\mathrm{AlGaAs} / \mathrm{GaAs}$.

область-теплоотводящее основание может быть описан с помощью закона теплопроводности Фурье [4]:

$$
\operatorname{grad}(T)=-\frac{\mathbf{q}}{\chi}
$$

где $\mathbf{q}$ - вектор плотности теплового потока, $\chi-$ теплопроводность структуры ФП.

Так, например, для ФП на основе $\mathrm{AlGaAs} / \mathrm{GaAs}$ c диаметром фотоприемной поверхности $300 \mu \mathrm{m}$ и толщиной кристалла $250 \mu \mathrm{m}$ при подводе непрерывного ЛИ мощностью $0.1 \mathrm{~W}\left(150 \mathrm{~W} / \mathrm{cm}^{2}\right)$ расчетная разница между температурой тыльного контакта и температурой $p-n$-перехода будет составлять в режиме холостого хода около $7^{\circ} \mathrm{C}$ (без отвода фотогенерированной энергии во внешнюю цепь). При увеличении мощности ЛИ на порядок (до $1 \mathrm{~W}$ или $1.5 \mathrm{~kW} / \mathrm{cm}^{2}$ ) эта разница будет достигать $76^{\circ} \mathrm{C}$. Соответственно стабилизация температуры тыльного контакта на уровне комнатной уже оказывается недостаточной, а поддержание температуры $p$-n-перехода на уровне $25^{\circ} \mathrm{C}$ приведет к переохлаждению подложки с сопутствующим этому состоянию изменением механизмов протекания тока.

При облучении модулированным по частоте ЛИ с увеличением скважности следования импульсов подводимая к ФП интегральная мощность падает. В этом случае возможен режим работы, при котором ФП будет нагреваться в период мощного импульса и остывать за время световой паузы. Изменение температуры за период одного импульса будет определяться как

$$
\Delta T=\frac{p D}{c m}
$$

где $P$ - мощность импульса, $D-$ коэффициент заполнения, $c$ - теплоемкость, $m$ - масса ФП.

Для рассматриваемого ФП с толщиной фотоактивных слоев $1 \mu \mathrm{m}$ изменение температуры $p-n$-перехода за импульс $300 \mathrm{~ns}$ составит около $1^{\circ} \mathrm{C}$ при пиковой мощности ЛИ $\sim 1 \mathrm{~W}\left(\sim 1.5 \mathrm{~kW} / \mathrm{cm}^{2}\right)$ без учета отведения тепла в подложку и окружающую среду.
Исследования выходных фотоэлектрических параметров проводились в квазистационарном режиме работы ФП (длительность светового импульса $300 \mathrm{~ns}$, частота следования $1 \mathrm{kHz}$, длина волны ЛИ $840 \mathrm{~nm})$, что позволило исключить нагрев $p-n$-перехода при увеличении мощности ЛИ, подводимой к образцу.

Уменьшение длительности импульсов ЛИ до единиц наносекунд оказалось нецелесообразным, поскольку в этом случае процессы генерации и рекомбинации неравновесных носителей заряда не успевают стабилизироваться в полной мере. Так, для GaAs время жизни неравновесных носителей заряда составляет $\sim 10 \mathrm{~ns}$, поэтому при длительности светового импульса 300 ns гарантируется квазистационарный режим работы ФП.

ФП с диаметром фотоприемной поверхности $300 \mu \mathrm{m}$ исследовались при мощности ЛИ 0.1-6W (облученность до $\sim 9 \mathrm{~kW} / \mathrm{cm}^{2}$ ) (рис. 2). Результаты исследований наглядно демонстрируют возможность эффективного (с КПД более 50\%) преобразования лазерного излучения ФП на основе $\mathrm{AlGaAs} / \mathrm{GaAs}$ при величине облученности до $2.5 \mathrm{~kW} / \mathrm{cm}^{2}$. Близкая к логарифмической зависимость напряжения холостого хода от облученности подтверждает изотермическое состояние тестируемых ФП во всем диапазоне подводимых мощностей ЛИ и регистрируемых фототоков: экспериментально продемонстрирована возможность достижения значений напряжения холостого хода более $1.3 \mathrm{~V}$ (плотность тока генерации $4.2 \mathrm{kA} / \mathrm{cm}^{2}$ ) для „холодного“ состояния ФП.

Таким образом, представлены результаты исследований фотоэлектрических параметров ФП лазерного излучения на основе $\mathrm{AlGaAs} / \mathrm{GaAs}$ в диапазоне высоких и сверхвысоких (до $9 \mathrm{~kW} / \mathrm{cm}^{2}$ ) пиковых облученностей при сохранении изотермического состояния $p-n$-перехода за счет импульсной подачи световой мощности. Режимы облучения подбирались таким образом,

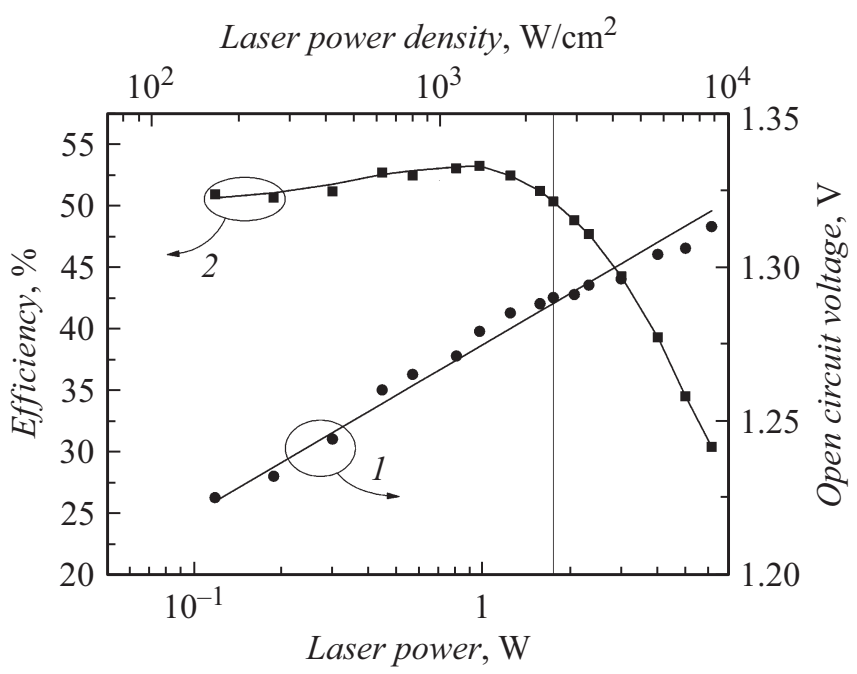

Рис. 2. Зависимость напряжений холостого хода (1) и КПД (2) от мощности (нижняя шкала) и от плотности мощности (верхняя шкала) ФП на основе $\mathrm{AlGaAs} / \mathrm{GaAs}$ с диаметром фоточувствительной области $300 \mu \mathrm{m}$. 
чтобы, с одной стороны, иметь скважность следования коротких лазерных импульсов, достаточную для уверенной записи экспериментальных данных, а с другой обеспечить значительное превышение длительности одиночного импульса над временем жизни неравновесных носителей заряда в тестируемом образце. Продемонстрирована возможность преобразования ЛИ $(840 \mathrm{~nm})$ с эффективностью более $51 \%$ при величине облученности до $2.5 \mathrm{~kW} / \mathrm{cm}^{2}$ для GaAs-элементов с площадью фоточувствительной поверхности $7 \cdot 10^{-4} \mathrm{~cm}^{2}$. Для исследуемых образцов максимальное значение КПД составило 54\% при мощности ЛИ, равной $1 \mathrm{~W}\left(1.5 \mathrm{~kW} / \mathrm{cm}^{2}\right)$.

Исследование выполнено за счет гранта Российского научного фонда (проект № 17-79-30035).

\section{Список литературы}

[1] Андреев В.М., Зайцев Д.Ф., Новиков Н.Ю., Калиновский В.С., Мордасов Д.В., Слипченко С.О., Тарасов И.С., Фадеев А.И. // Радиотехника. 2016. № 11. С. 177-183.

[2] Bett A.W., Dimroth F., Lockenhoff R., Oliva E., Schubert J. III-V solar cells under monochromatic illumination // Conference Record of the IEEE Photovoltaic Specialists Conference. IEEE, 2008. P. 1-5.

DOI: 10.1109/PVSC.2008.4922910

[3] Andreev V.M., Grilikhes V.A., Rumyantsev V.D. // Photovoltaic conversion of concentrated sunlight. John Willey\&Sons, 1997. P. 25.

[4] Landau L.D., Lifshitz E.M. // Theory of elasticity. Pergamon Press, 1986. P. 152. 